\title{
BONS CAMINHOS PARA CHEGAR AO TERMO: PROCESSO CENTRAL NO TRABALHO TERMINOLÓGICO VOLTADO PARA A TRADUÇÃO ENTRE A PRÁTICA E O ENSINO ${ }^{1}$
}

\author{
Felix Mayer
}

\begin{abstract}
This text discusses some aspects concerning terminological theory and practice. It starts from the questioning on how to find equivalent terms in the working languages. The phases and stages of the monolingual bilingual and/or multilingual terminological work are presented as well as some ways to help the collection and validation of terms in the target language after the terminological analysis in the source language such as the use of dictionaries and terminological termbanks, the intuitive term creation, horizontal and vertical approach and specialist consultation.
\end{abstract}

Key-words: terminological analysis, terminological work stages, terminological theory and practice.

\section{INTRODUÇÃO}

O trabalho terminológico está cada vez mais adquirindo importância e sendo valorizado. Tem-se exemplo claro dessa valorização em uma série de publicações, simpósios e eventos, ocorridos nos últimos anos, cujo tema central é o trabalho terminológico. Não se trata mais de apenas um pequeno e seleto grupo de terminólogos e tradutores que, já há décadas, se ocupa do tema. Ao contrário, pode-se constatar que, graças ao trabalho de associações como o Deutscher Terminologie-Tag (DTT e.V.) ${ }^{2}$, o Rat für deutsch-sprachige Terminologie (RaDT) ${ }^{3}$, uma iniciativa da UNESCO, ou ainda o Internationales Informationszentrum für Terminologie (Infoterm) ${ }^{4}$, outros grupos profissionais de várias áreas reconheceram a importância da terminologia (e continuam a reconhecer cada vez mais), ocupam-se do trabalho terminológico e buscam os melhores procedimentos.

Neste contexto, um antigo questionamento passa a ganhar um novo significado: O que a prática faz com a teoria e como a teoria se relaciona com essa prática?

Pois, na visão de um professor universitário, que elaborou alguns dicionários terminológicos, é insatisfatório quando a teoria é vista como "boa e bonita", mas não é aplicável ao seu trabalho terminológico. O objetivo de uma teoria ou ciência voltada para a prática é afinal apresentar respostas para os problemas da prática e não desenvolver teorias que sejam adequadas, mas que não tenham aplicação.

Dado esse contexto, o tema central deste artigo consiste em um questionamento específico em relação ao processo central do trabalho terminológico: Como encontramos a "denominação correta", ou seja, como chegamos ao outro lado e como e para onde vamos quando já temos

\footnotetext{
1 Título original: Der Kernprozess in der übersetzungsorientierten Terminologiearbeit zwischen Praxis und Lehre. Publicado em MAYER, Felix; REINEKE, Detlef; SCHMITZ, Klaus-Dirk (eds.). Best Practices in der Terminologiearbeit. Akten des Symposions, Heidelberg, 15.-17. April 2010. München, Köln: DTT, 2010. p.113-121. Tradução de Cristiane Krause Kilian; revisão de Luciane Leipnitz.

Felix Mayer é professor do Sprachen \& Dolmetscher Institut (SDI), na Hochschule für Angewandte Sprachen, München.

${ }^{2}$ Sociedade Alemã de Terminologia (N.T.).

${ }^{3}$ Conselho para Terminologia em Língua Alemã (N.T.).

${ }^{4}$ Centro Internacional de Informação para Terminologia (N.T.).
} 
esclarecido o conceito na Língua 1 (geralmente a língua de partida) e nos voltamos para a Língua 2 (geralmente a língua de chegada, quando se trata de um trabalho terminológico que acompanha uma produção textual)?

\section{FASES E ETAPAS DO TRABALHO TERMINOLÓGICO}

O trabalho terminológico como um processo completo é constituído de diferentes fases, as quais, por sua vez, são formadas por várias etapas. As principais fases, que foram introduzidas nos países de língua alemã por Reiner Arntz e Heribert Picht ${ }^{5}$, são (ver também Figura 1):

1. Planejamento

2. Fase principal e

3. Disponibilização para o usuário

\section{Língua 1}

\section{Língua 2}

\begin{tabular}{|c|c|c|}
\hline \multirow[t]{2}{*}{$\underline{\underline{D}}$} & \multicolumn{2}{|c|}{$\begin{array}{l}\text { Organização prévia do trabalho } \\
\text { Delimitação da área de especialidade e } \\
\text { segmentação em unidades menores }\end{array}$} \\
\hline & \multicolumn{2}{|c|}{ Construção e análise do corpus } \\
\hline \multirow{3}{*}{ 空. } & $\begin{array}{l}\text { Correspondência preliminar entre } \\
\text { conceito e denominação }\end{array}$ & $\begin{array}{l}\text { Correspondência preliminar entre } \\
\text { conceito e denominação }\end{array}$ \\
\hline & $\begin{array}{l}\text { Elaboração do sistema conceitual } \\
\text { em uma língua }\end{array}$ & $\begin{array}{l}\text { Elaboração do sistema conceitual } \\
\text { em uma língua }\end{array}$ \\
\hline & \multicolumn{2}{|c|}{$\begin{array}{l}\text { Análise terminológica bilíngue ou multilíngue, } \\
\text { estabelecimento de equivalências }\end{array}$} \\
\hline 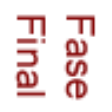 & \multicolumn{2}{|c|}{$\begin{array}{c}\text { Disponibilização para o usuário } \\
\text { (intranet, internet, dicionário impresso) }\end{array}$} \\
\hline
\end{tabular}

Fig. 1: Etapas do trabalho terminológico

Essas fases e cada uma de suas etapas, que podem ser estruturadas de maneira diferente ${ }^{6}$, estão estritamente ligadas ao tipo e aos objetivos do projeto terminológico. Assim, as Fases 1 e 3 , por exemplo, são estruturadas detalhadamente em um trabalho terminológico sistemático. Em um trabalho terminológico pontual, por exemplo, quando se trata de redação técnica ou tradução, no qual se busca "apenas" esclarecer um ou poucos conceitos, a Fase 3 consiste simplesmente em o usuário saber qual denominação deve ser utilizada no texto.

Assim, a metodologia descrita a seguir é considerada fundamental e deve ser adaptada de acordo com os objetivos do projeto.

\footnotetext{
${ }^{5}$ Ver Arntz e Picht (1982) e Arntz; Picht e Mayer (2009, 219 e seguintes).

${ }^{6}$ Ver Childress (2010, p. 45 e seguintes) e Pulitano (2010). Um panorama sobre as diferentes Escolas em Terminologia com seus diferentes procedimentos metodológicos e estruturação do trabalho terminológico encontra-se em Mayer (1998, p. 11 e seguintes) e Sappl (2010, p. 11 e seguintes).
} 


\section{Fase 1: Planejamento}

As considerações desta fase devem ser feitas antes do início do projeto terminológico e devem ser revistas antes de cada novo projeto. Em um trabalho terminológico sistemático, tais considerações exigem muita atenção, mesmo quando a experiência aponta para soluções rápidas. Em se tratando de um trabalho terminológico pontual, apenas algumas são relevantes e podem ser esclarecidas rapidamente.

As considerações durante a fase de planejamento se referem a:

1. objetivos, público-alvo, forma de utilização da terminologia, eventualmente forma de publicação e colaboração de especialistas no projeto,

2. (apenas para o trabalho terminológico sistemático:) delimitação da área de especialidade e segmentação em unidades menores, visto que uma quantidade muito grande de conceitos a serem trabalhados não permite que estes sejam analisados satisfatoriamente,

3. obtenção e análise do material para documentação; é importante que os textos

- sejam redigidos por especialistas,

- sejam escritos por falantes nativos e

- reflitam, com o seu conteúdo, o estado da arte da área de especialidade.

Os itens 1-3 são tipicamente considerados como as primeiras etapas do trabalho terminológico. São seguidos pelas etapas da Fase 2, que serão descritas no próximo item, e pela Fase 3, apresentada resumidamente a seguir.

\section{Fase 3: Disponibilização para o usuário}

Essa fase pode ser extremamente breve, mas também muito extensa. Em um trabalho terminológico monolíngue e pontual, o resultado pode corresponder ao termo a ser utilizado no texto. Em se tratando de uma abordagem multilíngue e sistemática, que provavelmente convirja em um sistema de gestão de conhecimento, o resultado é um banco de dados terminológicos estruturado de maneira bem complexa. E, se esse ainda for publicado em forma de dicionário, é evidente que nesta fase, em função de exigências distintas, surjam diferenças consideráveis.

\section{FASE 2: “ANÁLISE TERMINOLÓGICA” (FORMA CANÔNICA DO PROCESSO CENTRAL)}

O processo central do trabalho terminológico, a análise terminológica, constitui-se das seguintes etapas principais:

1. definição do conceito,

2. estabelecimento das relações entre os conceitos e

3. correspondência entre conceito e denominação, bem como busca ou elaboração de sinônimos (análise terminológica em sentido estrito).

No trabalho terminológico monolíngue, pode-se alcançar uma qualidade satisfatória com essas três etapas, que estão intimamente entrelaçadas e cuja ordem pode variar, (ver a figura a seguir referente à análise terminológica na Língua 1).

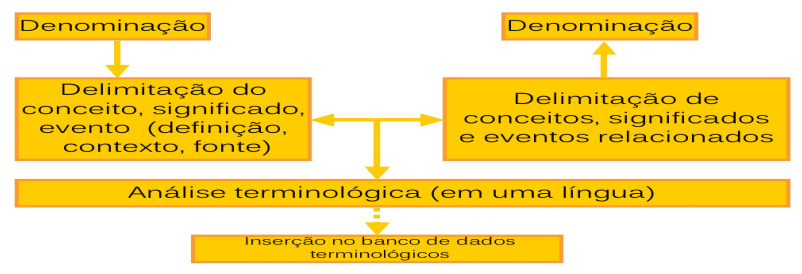

Fig. 2: Análise terminológica na Língua 1 
Mais complexo e difícil será o trabalho terminológico bilíngue e plurilíngue. Neste caso, de acordo com a teoria, as três etapas devem ser seguidas de modo independente por cada uma das línguas. Sob a perspectiva teórica, essa separação é necessária, pois o reconhecimento feito em uma língua não pode obstruir a visão da outra língua e as estruturas e hierarquias conceituais de uma língua não devem influenciar o olhar para a outra língua.

Segundo a teoria, apenas depois de definidos os conceitos e estabelecidas as relações entre eles, bem como estabelecida a correspondência entre o conceito e a denominação em cada uma das línguas, é que se deve proceder a comparação entre elas. Nesta análise comparativa dos termos, a equivalência entre os conceitos é constatada ou elaborada, o que ocorre com base nas posições no sistema conceitual e na comparação das definições correspondentes. Também se verifica se há e onde há lacunas conceituais ou denominativas, que eventualmente possam ser preenchidas.

Assim, a Fase 2, em um trabalho terminológico bilíngue, é constituída das seguintes etapas:

1. análise terminológica na Língua 1 (processo central na Língua 1),

2. análise terminológica na Língua 2 (processo central na Língua 2),

3. análise comparativa dos termos na Língua 1 e Língua 2.

A figura a seguir resume a Fase 2 - análise terminológica na Língua 1 e Língua 2:

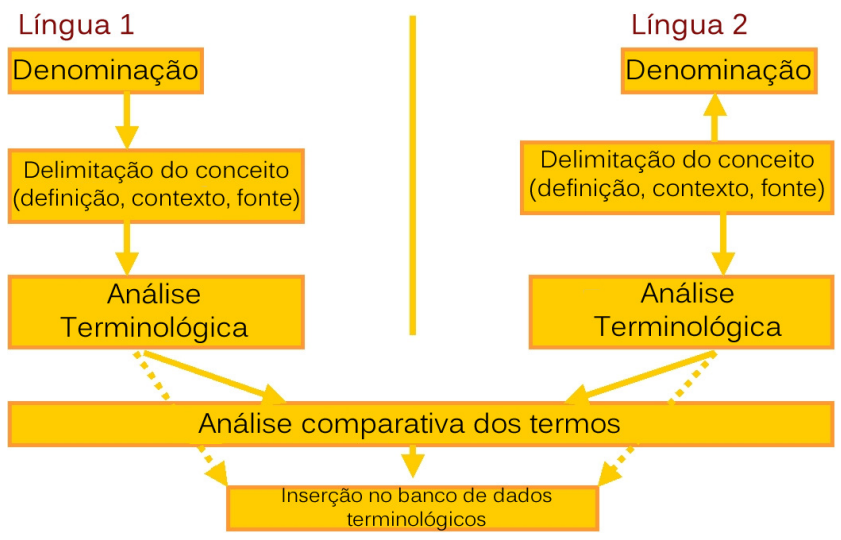

Fig. 3: Análise terminológica na Língua 1 e na Língua 2 e análise comparativa dos termos

A Fase 2 é seguida da Fase 3, que foi apresentada anteriormente e corresponde à disponibilização dos dados ao usuário.

\section{TÃO LONGE, TÃO PERTO: FORMAS PRAGMÁTICAS DO PROCESSO CENTRAL}

A seguir será apresentado o modo como se chega à Língua 2 após a análise terminológica na Língua 1, ou seja, em que direção devemos seguir, quando o conceito na Língua 1 já foi esclarecido (geralmente a língua de partida) e nos voltamos para a Língua 2 (geralmente a língua de chegada, em se tratando de um trabalho terminológico paralelo à redação de um texto). Qual é, então, o ponto de partida concreto para a pesquisa terminológica na Língua 2? Pois, o fato de o conhecimento adquirido na Língua 1 não ser considerado ao passarmos a trabalhar na Língua 2 não corresponde à prática.

São esboçados cinco caminhos ${ }^{7}$ considerados prototípicos. Para tanto, devem ser considerados os caminhos percorridos na prática. No entanto, deve-se ressaltar que, em um trabalho terminológico, apenas raramente eles aparecem isolados; com freqüência, se

\footnotetext{
${ }^{7}$ Ver Sappl (2010, p. 87 e seguintes).
} 
complementam.

Todos esses caminhos têm em comum o fato de oferecerem um ponto de partida para a análise terminológica na Língua 2, representada de forma resumida na figura a seguir:

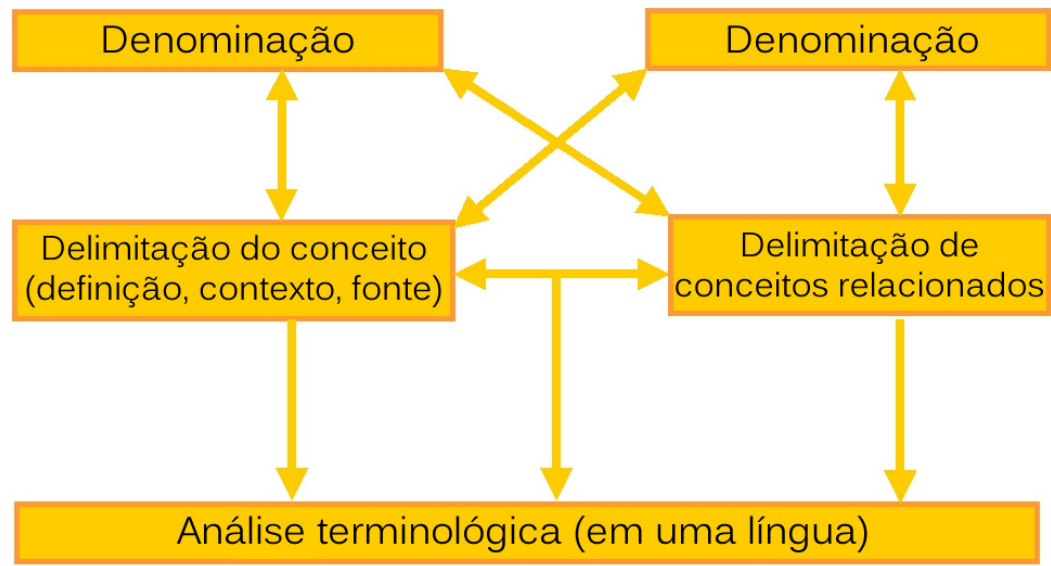

Fig. 4: Análise terminológica na Língua 2

\section{Uso de dicionários e banco de dados terminológicos}

A consulta a um dicionário (em formato impresso ou eletrônico) ou banco de dados terminológicos é uma prática comum. Profissionais experientes serão capazes de julgar se o equivalente apresentado está na direção certa ou não. A partir de uma ou mais denominações encontradas segundo esse procedimento é feita, então, a análise terminológica na Língua 2.

\section{Formação intuitiva da denominação ("um tiro no escuro")}

Competência, experiência, conhecimento e principalmente familiaridade com as regras de formação de palavras e unidades terminológicas possibilitam um "aventurar-se" em uma possível denominação na Língua 2. Na maioria das vezes, essa forma de se chegar ao termo é eficaz, quando a denominação na Língua 1 e a denominação na Língua 2 são formadas de maneira regular (regularidade da denominação) e quando, na passagem da Língua 1 para a Língua 2, for possível inferir ou construir as denominações a partir de regularidades.

\section{Abordagem horizontal}

Textos comparáveis são, segundo Hohnhold (1990, p. 24), textos "da mesma área de especialidade e de preferência da mesma categoria textual" que, em relação ao conceito na Língua 1, apresentam uma certa probabilidade de conter uma denominação na Língua 2, que documente o mesmo conceito ou pelo menos um conceito semelhante. Em relação a um texto na Língua 1 (que pode ser também apenas construído mentalmente), esses textos comparáveis encontram-se em um nível horizontal. Eles são analisados por um terminólogo, o que podemos chamar de "extração terminológica baseada na prática do terminólogo", e geralmente levam a um resultado "consistente".

\section{Especialista}

\footnotetext{
${ }^{8}$ Ver Arntz et al. (2009, p. 114 e seguintes) e Drewer (2010).
} 
A discussão com um especialista da área, que não necessariamente precisa saber as duas línguas, faz parte da análise terminológica e serve para o controle dos resultados esperados. Essa consulta pode ocorrer já em um estágio anterior: partindo da descrição do conceito na Língua 1, um especialista pode reconhecer se há uma denominação para um conceito correspondente (idêntico ou semelhante) na língua de chegada.

\section{Abordagem vertical}

Apenas raramente e no início do trabalho sobre a terminologia de uma área é necessário familiarizar-se com a área de especialidade e preparar o caminho, digamos, de cima para baixo. Nessa abordagem vertical, a partir de textos genéricos vai-se delimitando a área, através da análise de textos cada vez mais específicos. Essa abordagem é relativamente trabalhosa, pois se desenvolve do geral ao específico, sendo recomendada principalmente para o trabalho terminológico sistemático. Para um trabalho terminológico pontual, é raramente empregada, pois exige um esforço considerável.

\section{CONSIDERAÇÕES FINAIS}

Mesmo que à primeira vista possa parecer que os caminhos descritos questionam a teoria, que parece tão clara, eles correspondem apenas a um primeiro passo para a aproximação à outra língua, além de refletirem a prática. A esse primeiro passo segue-se a análise terminológica, na qual o conceito e a sua denominação são elucidados e, eventualmente, outros conceitos são analisados, até que se chegue a um resultado satisfatório. Isso não significa que a abordagem metodológica do trabalho terminológico, que, afinal, garante a qualidade, está sendo questionada. Essa abordagem ocorre apenas de maneira distinta: o fazer no trabalho terminológico é baseado na teoria, mas é realizado pragmaticamente e é, como em muitas outras atividades, orientado pelo conhecimento e pela experiência.

Dessa forma, deve ficar claro que a tensão aparente entre a teoria e a prática ("Não há trabalho terminológico, pois não há tempo, dinheiro...") não existe quando se trata de profissionais experientes: estes trabalham guiados pela teoria, que é a base do seu trabalho (e aqui pode-se fazer comparações com outras atividades práticas, como, p. ex., dirigir um carro) e não é necessariamente reconhecida em cada etapa. Tendo o conhecimento sobre o método e suas etapas, o profissional experiente irá verificar seus resultados (análise terminológica) até que tenha alcançado os resultados corretos e adequados. A teoria guia, mas não obriga.

No ensino, é exatamente isso que se deve transmitir: a abordagem metodológica, que leva a resultados validados e ajuda a evitar decisões precipitadas ("Mas está escrito!"). Mesmo que em sua estruturação concreta, essa abordagem recorra, p. ex., ao dicionário como forma de auxílio permitido, ela não fica nesse estágio, mas toma esse procedimento como base para dar continuidade - de maneira ágil e eficiente - às análises terminológicas.

\section{BIBLIOGRAFIA}

ARNTZ, Reiner; PICHT, Heribert. Einführung in die übersetzungsbezogene Terminologiearbeit. 1. Aufl. Hildesheim: Olms, 1982.

ARNTZ, Reiner; PICHT, Heribert; MAYER, Felix. Einführung in die Terminologiearbeit. 6. Aufl. Hildesheim: Olms, 2009.

CHILDRESS, Mark. Projekte und Prozesse der Terminologiearbei. In: MAYER, F.; REINEKE, D.; SCHMITZ, K-D. (eds.). Best Practices in der Terminologiearbeit. Akten des Symposions, Heidelberg, 15.-17. April 2010. München, Köln: DTT, 2010, p. 45-52. 
DREWER, Petra. Präskriptive Terminologiearbeit im Unternehmen. Bildung und Bewertung von Benennungen. In: MAYER, F.; REINEKE, D.; SCHMITZ, K-D. (eds.). Best Practices in der Terminologiearbeit. Akten des Symposions, Heidelberg, 15.-17. April 2010. München, Köln: DTT, 2010, p. 131-142.

HOHNHOLD, Ingo. Übersetzungsorientierte Terminologiearbeit. Eine Grundlegung für Praktiker. Stuttgart: Intra, 1990.

KRINGS, Hans P.; MAYER, Felix (eds.). Sprachenvielfalt im Kontext Fachkommunikation, Übersetzung und Fremdsprachendidaktik. Berlin: Frank \& Timme, 2008.

MAYER, Felix. Eintragsmodelle für terminologische Datenbanken. Ein Beitrag zur übersetzungsorientierten Terminographie. Tübingen: Narr, 1998.

MAYER, Felix. Terminographie heute. Antworten der Lehre auf die Anforderungen der Praxis. In: KRINGS, H. P.; MAYER, F. (eds.). Sprachenvielfalt im Kontext Fachkommunikation, Übersetzung und Fremdsprachendidaktik. Berlin: Frank \& Timme, 2008, p. 317-328.

MAYER, Felix. Terminologielehre und Terminologiemanagement. In: MAYER, F.; SEEWALD-HEEG, U. (eds.). Terminologiemanagement. Von der Theorie zur Praxis. Berlin: BDÜ, 2009, p. 12-26.

MAYER, Felix; SEEWALD-HEEG, Uta (eds.). Terminologiemanagement. Von der Theorie zur Praxis. Berlin: BDÜ, 2009.

MAYER, Felix; REINEKE, Detlef; SCHMITZ, Klaus-Dirk (eds.). Best Practices in der Terminologiearbeit. Akten des Symposions, Heidelberg, 15.-17. April 2010. München, Köln: DTT, 2010.

PULITANO, Donatella. Terminologische Grundsätze und Methoden. Wie viel Theorie verträgt die Praxis. In: MAYER, F.; REINEKE, D.; SCHMITZ, K-D. (eds.). Best Practices in der Terminologiearbeit. Akten des Symposions, Heidelberg, 15.-17. April 2010. München, Köln: DTT, 2010, p. 107-112.

REYAM, Xilef. Reflectione volante verba vs. manente scripta. Terminogia, comunicazon e solvaziones arrenti, In: KRINGS, H. P.; MAYER, F. (eds.). Sprachenvielfalt im Kontext Fachkommunikation, Übersetzung und Fremdsprachendidaktik. Berlin: Frank \& Timme, 2008, p. 329-331.

SAPPL, Sebastian. Wege zum rechten Term: Der intellektuelle Kernprozess bei der Terminologiearbeit. (Bachelor-Arbeit) Hochschule für Angewandte Sprachen. München: SDI, 2010. 